\title{
Effects of EGCG on Learning and Memory Abilities in mice with Alzeimer's Disease
}

\author{
Weiya Lang ${ }^{1}$, Zhongjin Liu ${ }^{2}$, Lihui Sun ${ }^{1}$,Danyang Liu ${ }^{1}$, Haiyan \\ Zhang $^{1}$ \\ ${ }^{1}$ Qiqihar Medical University, Qiqihar, China, 161000; ${ }^{2}$ first affiliated \\ hospital of Qiqihar medical University, Qiqihar, China, 161041 \\ *Corresponding Author: Haiyan Zhang
}

\begin{abstract}
Objective: To make a study of the effects of EGCG on learning and memory abilities in mice with Alzeimer's disease. Methods: The mice were divided into normal control group, model control group, brain repair group, low EGCG dose group, middle EGCG dose group and high EGCG dose group. We use the evaluation method of Morris water to study the learning and memory acquisition and the SOD activity and MDA content. Results: Compared with the model group, the incubation period of EGCG high dose group mice was significantly shorten; quadrant dwell time of high dose group and middle dose group were prolonged; the activity of SOD increased obviously in high dose of EGCG in serum of mice and the content of MDA in the high dose group in mice serum decreased obviously. Conclusion: EGCG can obviously prevent and improve the learning and memory dysfunction in mice.
\end{abstract}

Keywords: EGCG, Alzheimer's disease, animal model, learning and memory

\section{Introduction}

Alzheimer's disease (AD) has become the main cause of neural degeneration and dementia. AD mainly impairs learning and memory ability. The pathological features of senile plaques and neurofibrillary tangles appear in the central nervous system. Clinical symptoms include progressive mental retardation AD incidence increases sharply with age. The incidence of the elderly in the western developed countries over 85 years of age reaches about $30 \%$. With the acceleration of 
China's aging society, AD will become an important public health issue in the next twenty years. AD is a degenerative disease characterized by memory impairment and personality change. With the arrival of the aging society, the incidence of the disease is obviously increased, and the pathological changes of the tissues are marked. The establishment of a good animal model is helpful to explore the pathogenesis of the disease, early intervention of the disease and improve the curative effect. In this study, we used a novel compound acute AD model to study the effects of EGCG on learning and memory function in AD mice.

\section{Materials and Methods}

\subsection{Materials}

Morris water maze apparatus, 7500 quantitative PCR instrument (American ABI company), electrophoretic transfer membrane devices (American BioRad company), gel development system (Shanghai day products) EGCG (American Sigma company purity $>95 \%$ ), Rabbit anti mouse BACE1 polyclonal antibody in rabbits anti mouse TauS202S396 phosphorylation monoclonal antibody. EGCG is an ingredient extracted from Chinese Green Tea in Green Tea, it is the main activity and water soluble components, is the highest content of catechu components, accounting for Green Tea gross 9\%-13\%, because with solid special chemical structure, EGCG has very strong antioxidant activity, in cancer and cardiovascular disease as an important role. In addition, it can also be used as a reversal agent of tumor multidrug resistance, which can improve the sensitivity of cancer cells to chemotherapy and reduce the toxicity to heart. Reverse transcriptase PCR primer sequence was synthesized by Shanghai Bioengineering Co., 1td. 40 SAMP8 mice, SAMR1 mice 20, mice were male, February age, certificate number: SCXK 2016 - 0001 experimental set 3 groups, 20 rats in each group, respectively, model group (from February to August at the age of normal feeding old SAMP8 mice EGCG group since February, at the age of drink water, join EGCG, $2 \mathrm{mg} / \mathrm{kg}$ every day, for 6 months) and control group (from February to August at the age of normal feeding old SAMR1 mice) after feeding, the first Morris water maze test, and then after killed mice, rapid separation of brain tissue, saline wash. The tissue is stored in the cortex and hippocampus of separation in $1.5 \mathrm{~mL}$ centrifuge tube in $30 \mathrm{~min}$ at $-80^{\circ} \mathrm{C}$.

\subsection{Methods}

The half of the 60 SAMP mice is male and the others are female. They were randomly divided into 6 groups, namely normal control group, model group, group and EGCG groups. Each group is 10. In addition to the normal control group were injected with saline and other groups were given daily injection of $120 \mathrm{mgkg}$ and sodium nitrite $90 \mathrm{mgkg}$ for four weeks. EGCG medium dose group were orally given EGCG. We examined long-term memory function. In the navigation experiment, the centre of the SW quadrant was selected as the entry 
point, and the mice were put into the water into the pool wall. After an interval of 10 min removal station, space exploration experiment. The site will be removed, also chose SW quadrant of the centre as the entry point, the mouse into the wall gently into the water, record the 60s inner NE Quadrant for platform time. After the water maze experiment, the eyeballs were collected and the activity of SOD and the content of MDA were determined according to the kit. We use SPSS11.5 statistical software for data analysis. The experimental data are expressed as mean standard deviation SD. The comparison of multiple groups were analysed by one-way analysis of variance. Cmpared with the LSD method, the sample average is $\mathrm{P}<0.05$ as the difference was statistically significant.

\section{Results}

\subsection{Effects of EGCG on learning and memory abilities}

Effects of EGCG on learning and memory in mice are shown in table 1. Compared with the blank control group, model group for the platform was significantly prolonged $(\mathrm{P}<0.05)$, where the original NE platform quadrant time was shortened $(\mathrm{P}<0.05)$ compared with the model group, high dose of EGCG group for the platform was significantly shortened $(\mathrm{P}<0.05)$, EGCG high dose group of the original platform the NE quadrant was prolonged $(\mathrm{P}<0.05)$. Normal control group and sham operation group mice had no significant difference in latency and number of errors. Compared with the sham operation group, the latency of the AD model group was significantly shortened, the number of errors was significantly increased $(\mathrm{P}<0.01)$. The injection could cause damage to the passive avoidance ability of mice. Compared with the AD model group, polyprenols $40,80 \mathrm{mgkg}^{-1}$ dose group mice showed a prolonged latent period and number of errors decreased significantly $(\mathrm{P}<0.05$ or 0.01$)$, and high dose of polyprenols $\left(80 \mathrm{mg} / \mathrm{kg}^{-1}\right)$ similar. The $0.3 \mathrm{mg} / \mathrm{kg}^{-1}$ effect of pine needles can improve the ability of passive avoidance memory in AD mice. The effects of EGCG on learning and memory abilities are shown in Table 1. 
Table 1 Effects of EGCG on learning and memory abilities

\begin{tabular}{lllll}
\hline Group & $\begin{array}{l}\text { Number } \\
\text { of mice }\end{array}$ & $\begin{array}{l}\text { Dose } \\
(\mathrm{g} / \mathrm{kg})\end{array}$ & $\begin{array}{l}\text { Incubation period } \\
(\mathrm{s})\end{array}$ & $\begin{array}{l}\text { Quadrant } \\
\text { dwell time }\end{array}$ \\
\hline $\begin{array}{l}\text { High dose group } \\
\text { of ECGC }\end{array}$ & 10 & 10 & $29.02 \pm 7.59$ & $38.21 \pm 2.52$ \\
$\begin{array}{l}\text { Middle dose } \\
\text { group of ECGC }\end{array}$ & 10 & 6 & $32.26 \pm 13.94$ & $26.25 \pm 13.35$ \\
$\begin{array}{l}\text { Low dose group } \\
\text { of ECGC }\end{array}$ & 10 & 3 & $35.28 \pm 9.64$ & $22.19 \pm 3.77$ \\
$\begin{array}{l}\text { Brain } \\
\text { group repair }\end{array}$ & 10 & 1 & $21.63 \pm 7.88$ & $39.41 \pm 8 / 09$ \\
$\begin{array}{l}\text { Model group } \\
\text { Normal group }\end{array}$ & 10 & - & $40.86 \pm 12.21$ & $17.93 \pm 2.88$ \\
\hline
\end{tabular}

\subsection{Effects of EGCG on SOD activity and MDA content}

Compared with the blank control group, model group, SOD activity decreased significantly $(\mathrm{P}<0.01)$, the contents of MDA increased significantly $(\mathrm{P}<0.05)$ compared with the model group, high dose of EGCG SOD activity increased significantly $(\mathrm{P}<0.01)$. The EGCG high dose MDA decreased significantly $(\mathrm{P}<$ $0.01)$. The results are shown in Table 2.

Table 2 Effects of EGCG on different dose

\begin{tabular}{ccccc}
\hline Group & $\begin{array}{c}\text { Number } \\
\text { of mice }\end{array}$ & $\begin{array}{c}\text { Dose } \\
(\mathrm{g} / \mathrm{kg})\end{array}$ & $\begin{array}{c}\text { SOD } \\
(\mathrm{U} / \mathrm{ml})\end{array}$ & MDA $(\mu)$ \\
\hline $\begin{array}{c}\text { High dose group of } \\
\text { ECGC }\end{array}$ & 10 & 10 & $236.23 \pm 9.28$ & $7.87 \pm 0.14$ \\
$\begin{array}{c}\text { Middle dose group of } \\
\text { ECGC }\end{array}$ & 10 & 6 & $205.69 \pm 7.46$ & $7.98 \pm 0.38$ \\
$\begin{array}{c}\text { Low dose group of } \\
\text { ECGC }\end{array}$ & 10 & 3 & $198.65 \pm 3.42$ & $3.18 \pm 0.86$ \\
$\begin{array}{c}\text { Brain repair group } \\
\text { Model group }\end{array}$ & 10 & 1 & $296.95 \pm 6.98$ & $7.07 \pm 0.13$ \\
$\quad 10$ & - & $154.55 \pm 5.88$ & $8.41 \pm 0.03$ \\
Normal group & 10 & - & $196.31 \pm 10.21$ & $5.37 \pm 0.48$ \\
\hline
\end{tabular}

\section{Discussion}

EGCG is one of the main bioactive compounds of tea polyphenols, which has antioxidant, antitumor and cardiovascular functions. The main symptoms of Alzheimer's disease of memory and cognitive impairment of speech disorders psychomotor abnormalities and other symptoms, the majority of scholars believe that there are many reasons about $\mathrm{AD}$ the cholinergic damage theory in the pathogenesis. It is closely related to the severity of dementia. Free radical damage 
theory is one of the important pathogenesis of AD. Under normal circumstances, the human body oxygen metabolism process produces a low concentration of free radicals. However, if too much or the elimination of the ability to reduce, it will cause harm to the body of patients with $\mathrm{AD}$ superoxide dismutase activity decreased, leading to increased oxidative stress, free radical deposition. Oxygen free radicals in the body too much can attack damage the nerve cell membrane, interfere with the normal function of intracellular enzymes system, causing nerve cell aging and degeneration, eventually lead to the occurrence of AD. Hypoxia ischemia sodium nitrite injection can cause systemic multi organ, cause learning and memory decline. In this experiment, Morris water maze test the model of learning and memory function of mice. The results showed that the SOD model mice were found to be significantly longer than the latency of the site, the site of the original quadrant of the residence time shortened significantly, such as the decline of brain function and the performance of AD. MDA content increased significantly. The results show that the free radical damage is an important cause of brain function decline and injury. In this study, we observed the effects of EGCG on learning and memory, SOD activity and MDA content in serum of AD mice. The latency period of EGCG high dose group mice was significantly shorter, and the residence time was significantly longer in the original platform. Serum SOD activity was significantly increased, MDA content decreased.

\section{Conclusion}

EGCG can obviously prevent and improve the learning and memory dysfunction in mice induced by D-galactose and sodium nitrite. The mechanism of action may be related to its ability to alleviate and reverse the production of oxygen free radicals. It can accelerate the elimination of lipid peroxidation in the body, and reduce the oxidative damage of oxygen to brain tissue. The mechanism of EGCG to improve the learning and memory function of $\mathrm{AD}$ may be multiple targets, and needs to be further studied.

\section{Acknowledgement}

The research was financially by Natural Science Foundation of Heilongjiang Province(H2016101).

\section{References}

[1] Yi Hui, Protective Effects of Panax notoginseng Extracts on Alzheime's disease Model Mice, China Pharmacy, 22(39), pp. 3667-3668, 2011.

[2] Sui Lu, Chen Duo, Jin Ge, Effects of EGCG on nerve protection and BACE1 expression level in hippocampus of mice with Alzheimer's disease, Chinese Journal of Public Health, 30(10), pp. 1282-1284, 2014. 
[3] Shi Chengnan, Li Xiuguo, Xu Qingsong, Jin Yuanzhe, Jiang Wankui, Effects of polygala tenuifolia extracts on learning and memory abilities in Alzeimer s disease model mice, Journal of Apoplexy and Nervous Diseases, 28(7), pp. 620622, 2011.

[4] Zhao Jin, Cai Zhaowei, Guan Feng, Alzheimer's disease and PRNP mutational mouse models, Acta Laboratorium Animalis Scientia Sinica, 24(5), pp. 541-545, 2016. 